\title{
Liver disease in ulcerative colitis: an epidemiological and follow up study in the county of Stockholm
}

\author{
U Broomé, H Glaumann, G Hellers, B Nilsson, J Sörstad, R Hultcrantz
}

\begin{abstract}
In an epidemiological study of the incidence of ulcerative colitis (UC) in the county of Stockholm between 1955 and 1979, 1274 patients with UC were discovered. Almost all these patients had regularly been investigated with liver function tests; $142(11 \%)$ of them showed signs of hepatobiliary disease. A follow up study on all 142 patients with abnormal liver function and UC was made between 1989 and 1991 to evaluate the cause of the liver abnormality and to find out if the liver disease had affected the survival rates. At follow up, eight patients were reclassified as having Crohn's disease, 60 had developed normal liver function as judged from test results, while the remaining 74 still had signs of hepatobiliary disease. The most common explanation for a transient abnormality in liver function was active colitis. The temporary signs of liver injury were not associated with changes in survival rates for these patients. Infections, especially those because of hepatitis $B$ and
\end{abstract} $C$ virus transmitted by blood transfusions accounted for the abnormalities in liver function in 21 patients, nine of which had a chronic, but non-fatal course. Twenty nine $(2 \cdot 3 \%)$ of the patients developed primary sclerosing cholangitis (PSC), and 12 of them died during the study period four because of cholangiocarcinoma and eight because of hepatic failure; one patient had a transplant. The estimated median time of survival from the first presentation of evidence of a liver function, compatible with the diagnosis of PSC, to death or liver transplantation was 21 years. A comparison of survival rates in patients with $U C$ and patients with UC and concurrent PSC showed, a significant reduction in survival in the PSC group $(p<0.0001)$. The number of patients with UC who developed PSC remained constant during the study period. Thus, although evidence of abnormal liver function is a common finding in UC, a spontaneous return to normal levels is common. In this study, which did not have a selection bias, the median time of survival among PSC patients was far longer than previously described although development of PSC among patients with UC does significantly reduce the estimated median time of survival.

(Gut 1994; 35: 84-89)

The association of ulcerative colitis (UC) and liver disease was first described in 1873 and was followed by numerous surveys of liver dysfunction in UC. ${ }^{1-3}$ A number of liver disorders, such as fatty change, chronic autoimmune hepatitis, liver cirrhosis, cholangiocarcinoma, and primary sclerosing cholangitis (PSC) are said to be more common in patients with UC. ${ }^{47}$ The incidence of these complications varies in different studies depending on selection criteria and on the definition of hepatobiliary disease. ${ }^{89}$ The true incidence of hepatobiliary dysfunction in UC, however, can only be obtained by tests of liver function tests such as transaminases, alkaline phosphatases, and bilirubin made routinely in unselected groups of patients with UC. Because the cause of hepatic involvement in UC is enigmatic it is important to find out if the rate of this complication is increasing, because of factors unrelated to UC, or if it mirrors the incidence of UC in itself.

Although it is well established that PSC is a harmful disease often associated with $\mathrm{UC}^{10} 11$ the importance of pathological liver function tests among patients with UC has yet to be established. To find out if hepatobiliary dysfunction affects the survival of patients suffering from $\mathrm{UC}$, it is necessary to study the patients for a long period of time.

In a previously reported epidemiological study, ${ }^{12} 1274$ patients with UC were identified in the county of Stockholm between 1955 and 1979 . These patients were subsequently investigated for morbidity and mortality with regard to liver function. In this group, 142 patients were found to have abnormal liver function tests and all of them were studied for an average of 15 years after the onset of abnormal liver function tests.

The aims of this study were to establish the cause of the liver function abnormalities in all 142 patients and to find out whether or not the liver disease affected the survival of the patients.

\section{Patients and methods}

The basis for this study is an epidemiological investigation of the incidence of UC in Stockholm county over a 25 year period. ${ }^{12}$ Only patients having a definite diagnosis of UC between 1955 and 1979 and who were residing in Stockholm at the time of the diagnosis were included. A total of 1274 patients, 681 males and 593 females, with UC were found. ${ }^{13}$ Twenty five per cent of the patients suffered from proctitis, defined as mucosal changes found at proctosigmoidoscopy, with a clear definition between the affected rectal mucosa and the normal mucosa in more proximal parts of the colon and a barium enema without further pathology. Thirty eight per cent presented with mucosal changes in the rectum and radiological changes in the distal colon (reaching in proximal direction no further than to the hepatic flexure) and were defined as having left sided colitis. Thirty seven per cent of the patients had total colitis, defined as mucosal changes in the rectum and radiological evidence 
of disease in the colon beyond the hepatic flexure. All but 55 patients were regularly investigated with liver function tests. Patients with evidence of abnormal liver function tests (at least twice the upper normal values of serum bilirubin, serum activities of alkaline phosphates, or liver transaminases, or all three at two occasions with a minimal interval of two months) were defined as having hepatobiliary disease. Onset of liver disease was defined as the time of the first abnormal liver function tests. One hundred and forty two patients, 92 males and 50 females, with UC and abnormal liver function tests were identified.

\section{METHODS}

The files from all 142 patients, both living and deceased $(n=35)$, with UC and signs of hepatobiliary disease were re-evaluated during the years 1989 and 1991. If no current data were available, patients were asked to have liver function tests. If no clinical signs of liver disease were present and aspartate aminotransferase and alanine aminotransferase were $<1.0 \mu \mathrm{kat} / \mathrm{l}$ and alkaline phosphatase $<5.0 \mu \mathrm{kat} / \mathrm{l}$ no further investigation was carried out. Attempts were made to retrospectively clarify the cause of the previous abnormalities in liver function tests.

All patients with a persistent rise in alkaline phosphatase $>5 \mu \mathrm{kat} / \mathrm{l}$ (normal upper range $<4 \cdot 2 \mu \mathrm{kat} / \mathrm{l})$ had an ultrasound investigation and subsequently also an endoscopic retrograde cholangiography or percutaneous transhepatic cholangiography.

All patients with a persistent rise in transaminase activities and without a previously established hepatobiliary diagnosis were examined with conventional laboratory tests and were questioned concerning intake of alcohol or drugs, and exposure to other hepatotoxic substances. Laboratory tests included assessment of serum $\gamma$-glutamyltransferase, bilirubin, creatinine and ferritin, and serum protein electrophoresis regarding values of ceruloplasmin and $\alpha_{1}$ anti-trypsin. Immunofluorescence analyses of smooth muscle anti-nuclear and anti-mitochondrial antibodies were made. Serological tests for hepatitis B (HBsAg, anti-HBs, and anti$\mathrm{HBc}$ ) and hepatitis $\mathrm{C}$ (anti-HCV, RIBA-1) were done with routine techniques. All patients had ultrasonography. With one exception, a postmortem examination was done on all deceased cases. Time for follow up was defined as the time for final investigation, death or liver transplantation.

\section{DEFINITION OF DIAGNOSTIC CRITERIA}

PSC was the diagnosis if cholangiographic findings of strictures or irregularities in the intrahepatic or extrahepatic bile ducts, or both were found. ${ }^{14}$ A liver biopsy specimen was subsequently obtained for these patients. The onset of disease was defined as the time of first presentation of abnormality of liver function tests consistent with a diagnosis of PSC.

For the diagnosis of autoimmune hepatitis a liver biopsy compatible with chronic active hepatitis, circulating antibodies against nuclei and smooth muscle, raised IgG, and negative tests for hepatitis $B$ was required. ${ }^{15}$

Positive markers for hepatitis B (presence of surface antigen and antibodies to core antigen) or antibodies to hepatitis $\mathrm{C}$, proved with the recombinant immunoblot analysis (RIBA C100-3, Chiron) and a liver biopsy compatible with chronic viral hepatitis were interpreted as indicative of chronic hepatitis B or C infection.

The patients were diagnosed as having a liver abnormality as a result of active colitis if evidence of abnormal liver function tests was found only during periods of inflammatory activity in the bowel, as defined by diarrhoea and sigmoidoscopic findings of excess mucus, signs of bleeding, or ulcerations, or all three and if the liver function tests returned to normal after colectomy or when the patients were in remission and no other explanation for the abnormality in liver function tests was found. Fatty change was believed to be the cause of increased activities of transaminases if the patients showed an isolated increase in these enzymes unrelated to inflammatory activity in the bowel, were overweight (calculated from as weight $(\mathrm{kg}) /$ length $(\mathrm{cm})$ $100>1$ ), and with no other explanation for abnormal liver function tests, such as alcohol abuse. ${ }^{16}$

All slides from biopsy specimens and liver tissue obtained at necropsy were re-evaluated by one liver pathologist (HG) and one hepatologist (UB) according to the international classification of liver diseases and without knowledge of the clinical data concerning the patients. ${ }^{17}$

\section{STATISTICAL ANALYSES}

Student's $t$ test was used to compare mean values, and $\chi^{2}$ analysis to compare proportions. Survival curves were estimated by the method of Kaplan and Meyer and differences between groups were compared using the log rank test. As the development of PSC can be considered to be time dependent after the development of UC, an analysis of survival curves for patients with both PSC and UC, and patients with UC alone, was done after a study period of 48 months. The study period and the follow up period were then kept apart. ${ }^{18}$

\section{Results}

The male to female ratio was 588/544 among the patients with UC but without evidence of liver disease, compared with 93/49 among patients with liver disease $(p<0 \cdot 002)$. Three hundred and sixty nine patients without liver disease had a total colitis, compared with 107 of the patients with hepatobiliary disease $(p<0.0001)$. The mean age at onset of UC did not differ significantly between patients with and without liver disease.

All patients could be traced for follow up. Eight were re-evaluated and reclassified as having Crohn's disease and were therefore excluded from further investigation. The rest of the patients (134) were categorised according to the presence or absence of evidence of abnormal liver function tests at follow up. Figure 1 summarises the results. 


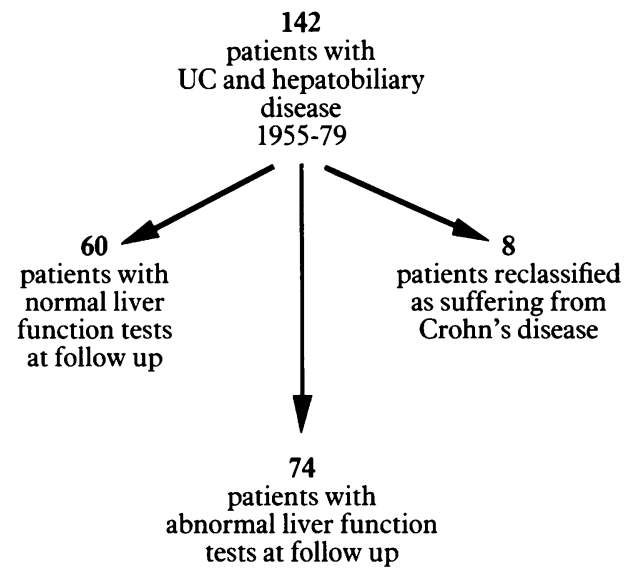

Figure 1: The results from the follow up of 142 patients with ulcerative colitis $(U C)$ and evidence of abnormal liver function tests.

NORMAL LIVER FUNCTION TESTS AT FOLLOW UP Sixty patients were found to have had a transient disturbance of liver function tests (which had resolved). Table I shows data from these patients. The abnormal liver function tests were usually found during periods of active inflammation in the colon. Forty patients ( 19 males and 21 females) most of whom had total colitis, also showed evidence of abnormal liver function tests during periods of chronic continuous or fulminant colitis. All these 40 patients had raised transaminase activities and 13 had raised alkaline

TABLE I Clinical data from patients with a transient rise in LFT and with normal LFT at follow up

\begin{tabular}{lcllllll}
\hline & & & $\begin{array}{l}\text { Median age } \\
\text { at onset of } \\
\text { UC }(y)\end{array}$ & $\begin{array}{l}\text { Median age } \\
\text { at onset of } \\
\text { liver disease } \\
(y)\end{array}$ & $\begin{array}{l}\text { No of } \\
\text { patients } \\
\text { with total } \\
\text { colitis }\end{array}$ & $\begin{array}{l}\text { Time of } \\
\text { follow up } \\
(y)\end{array}$ & $\begin{array}{l}\text { No of } \\
\text { patients } \\
\text { who had } \\
\text { died }\end{array}$ \\
\hline Active colitis & 40 & $19 / 21$ & $30(9-69)$ & $32(9-73)$ & 33 & 18 & $3^{\star}$ \\
Hepatitis B & 4 & $3 / 1$ & $33(31-44)$ & $36(31-45)$ & 2 & 19 & 0 \\
CMV & 3 & $2 / 1$ & $16(9-18)$ & $24(16-32)$ & 2 & 13 & 0 \\
Fatty infiltration & 3 & $3 / 0$ & $30(22-37)$ & $30(22-38)$ & 3 & 18 & 0 \\
Abscess & 3 & $2 / 1$ & $22(21-40)$ & $36(22-40)$ & 3 & 13 & 0 \\
Cholecystitis & 2 & $1 / 1$ & 30 & 32 & 0 & 17 & 0 \\
Drug reaction & 2 & $2 / 0$ & 41 & 48 & 1 & 15 & 0 \\
Hepatitis A & 1 & $1 / 0$ & 30 & 36 & 1 & 27 & 0 \\
Coeliac disease & 1 & $0 / 1$ & 27 & 45 & 0 & 14 & 0 \\
Pregnancy & 1 & $0 / 1$ & 18 & 19 & 0 & 12 & 0 \\
\hline
\end{tabular}

$\star$ Deaths unrelated to liver disease; $\mathrm{LFT}=$ liver function tests; $\mathrm{UC}=$ ulcerative colitis; $\mathrm{CMV}=$ cytomegalovirus.

TABLE II Clinical data from patients with ulcerative colitis (UC) and abnormal LFT at follow up. (PSC patients excluded)

\begin{tabular}{|c|c|c|c|c|c|c|}
\hline & $n=45$ & $\begin{array}{l}\text { Sex } \\
M / F\end{array}$ & $\begin{array}{l}\text { Median } \\
\text { age at } \\
\text { presentation } \\
\text { of } U C(y)\end{array}$ & $\begin{array}{l}\text { Median age } \\
\text { at presentation } \\
\text { of liver disease } \\
(y)\end{array}$ & $\begin{array}{l}\text { No of } \\
\text { patients } \\
\text { with total } \\
\text { colitis }\end{array}$ & $\begin{array}{l}\text { No of } \\
\text { patients } \\
\text { who had } \\
\text { died }\end{array}$ \\
\hline Fatty liver & 11 & $11 / 0$ & $28(8-58)$ & $28(17-58)$ & 7 & 2 \\
\hline Alcoholic overconsumption & 9 & $7 / 2$ & $39(13-66)$ & $44(27-66)$ & 5 & 7 \\
\hline Chronic hepatitis C & 8 & $5 / 3$ & $21(13-63)$ & $26(13-63)$ & 8 & 0 \\
\hline $\begin{array}{l}\text { Carcinoma with liver } \\
\text { metastasis }\end{array}$ & 4 & $2 / 2$ & $36 \cdot 5(12-41)$ & $38(29-41)$ & 4 & 4 \\
\hline Chronic autoimmune & & & & & & \\
\hline $\begin{array}{l}\text { hepatitis } \\
\text { has }\end{array}$ & 3 & $2 / 1$ & $25(18-26)$ & $30(25-37)$ & 3 & 0 \\
\hline Heart failure & 2 & $2 / 0$ & $59(45-72)$ & $66(59-72)$ & 1 & 2 \\
\hline Gilbert's syndrome & 2 & $2 / 0$ & $40(24-56)$ & $40(24-56)$ & 2 & 1 \\
\hline Chronic hepatitis B & 1 & $1 / 10$ & 50 & 36 & 0 & 0 \\
\hline Hepatic cysts & 1 & $0 / 1$ & 11 & 11 & 1 & 0 \\
\hline Primary biliary cirrhosis & 1 & $0 / 1$ & 51 & 1 & 1 & 1 \\
\hline Hepatoma & 1 & $1 / 0$ & 30 & 41 & i & 1 \\
\hline Liver cirrhosis & 1 & $0 / 1$ & 12 & 12 & 1 & 1 \\
\hline Unclear & 1 & $0 / 1$ & 20 & 20 & 0 & 0 \\
\hline
\end{tabular}

LFT = liver function tests; $P S C=$ primary sclerosing cholangitis . phosphatase activities as well. Twenty one of these patients had colectomy. Postoperatively, liver function - based on the results of liver function tests - returned to normal. Six of the patients with abnormal liver function tests related to active colonic inflammation had liver biopsy specimens taken. Fatty change was found in all six biopsy specimens, and portal mononuclear cell infiltration was noted in two.

All patients with acute hepatitis $B(n=4)$ and cytomegalovirus $(n=3)$ infection had received blood transfusions, either in association with colectomy or during periods of active colitis. Two patients with fulminant colitis at the time of colectomy were found to have liver abscesses, and one subsequently developed a subphrenic abscess. Thus, 10 patients had had infectious diseases which might explain the transient abnormalities in liver function tests.

Fatty change was suspected in two patients and verified by liver biopsy examination in one. All three patients showed a protracted rise in transaminases; however, subsequently, normal values were regained after weight reduction. Signs indicative of drug reaction against sulphasalazine were noted in two patients. Both reacted with evidence of abnormal liver function tests shortly after the onset of sulphasalazine treatment; a return to normal soon occurred after the drug was stopped. The same reaction was seen when sulphasalazine was reintroduced.

ABNORMAL LIVER FUNCTION TESTS AT FOLLOW UP Seventy four patients had abnormal liver function tests at follow up. Tables II and III give the clinical data from these patients.

Fatty liver was believed to be present in five patients, and was morphologically verified in four after liver biopsy examination. It was also shown at postmorten examination in another two patients who died as a result of causes unrelated to liver disease. Excess consumption of alcohol was found in nine patients; five of them died because of liver failure. A substantial male predominance was found concerning fatty change and alcohol related liver disease.

Eight patients suffered from chronic hepatitis $C$ infection and one had a chronic hepatitis B infection, all having received blood transfusions during periods of active colitis or when having a colectomy. Chronic autoimmune hepatitis was found in three patients - all steroid dependent. Primary biliary cirrhosis was diagnosed in one patient. One female patient with cirrhosis of unknown cause died during colectomy. The liver was found to be small and cirrhotic at laparotomy; however, no biopsy specimen was taken and a necropsy was not done. Another patient, with an unclear cholestatic liver disease, suffered from chronic psychiatric disease and received prolonged anti-psychotic drug treatment. Endoscopic retrograde cholangiopancreatography (ERCP) had previously shown normal bile ducts; but the patient refused further investigation. Table II lists various additional liver diagnoses, which are not known to be related to UC.

The most common cause for persistent abnormal liver function tests was primary sclerosing cholangitis, found in 27 patients 
TABLE III Clinical data from all patients with primary sclerosing cholangitis (PSC)

\begin{tabular}{llllll}
\hline & & \multicolumn{5}{l}{$\begin{array}{l}\text { Median age } \\
\text { at onset of }\end{array}$} & $\begin{array}{l}\text { Median age } \\
\text { at onset of }\end{array}$ \\
& $n=29$ & $M / F$ & $U C(y)$ & $P S C(y)$ & Colectomy \\
\hline Patients still alive & 14 & $12 / 2$ & $16(4-40)$ & $24(7-51)$ & 5 \\
Patients dead or who had a transplant & 9 & $7 / 2$ & $21(10-48)$ & $27(7-48)$ & 3 \\
Patients who died with cholangiocarcinoma & 4 & $4 / 0$ & $42(15-65)$ & $45(21-56)$ & 1 \\
Small bile duct sclerosing cholangitis & 2 & $1 / 1$ & 23 & 33 & 0 \\
\hline
\end{tabular}

$\mathrm{UC}=$ ulcerative colitis.

TABLE IV Causes of death among patients with ulcerative colitis and liver disease

\begin{tabular}{|c|c|c|c|c|}
\hline & $\begin{array}{l}\text { Dead } \\
\text { between } \\
1955-79\end{array}$ & $\begin{array}{l}\text { Median } \\
\text { age at } \\
\text { death }(y)\end{array}$ & $\begin{array}{l}\text { Dead } \\
\text { between } \\
1980-91\end{array}$ & $\begin{array}{l}\text { Median age } \\
\text { at death } \\
\text { (y) }\end{array}$ \\
\hline $\begin{array}{l}\text { Liver failure because of PSC } \\
\text { PSC+cholangiocarcinoma } \\
\text { Liver failure because of alcoholic } \\
\text { overconsumption } \\
\text { Hepatoma } \\
\text { Heart failure or myocardial infarction, or } \\
\text { both } \\
\text { Postoperative complication } \\
\text { Carcinoma of the colon } \\
\text { Carcinoma of the ovary or testis } \\
\text { Gastrointestinal bleeding } \\
\text { Sepsis } \\
\text { Pulmonary embolism }\end{array}$ & $\begin{array}{l}2 \\
2 \\
3 \\
1 \\
2 \\
1 \\
1 \\
2 \\
1 \\
0 \\
0 \\
15\end{array}$ & $\begin{array}{l}37(27-47) \\
57(41-72) \\
\\
63(59-71) \\
46 \\
62 \cdot 5(60-65) \\
61 \\
29 \\
44 \\
50\end{array}$ & $\begin{array}{l}7^{\star} \\
2 \\
2 \\
0 \\
4 \\
1 \\
2 \\
0 \\
0 \\
1 \\
1 \\
20\end{array}$ & $\begin{array}{l}78(68-90) \\
64 \\
60(47-73)\end{array}$ \\
\hline
\end{tabular}

*One patient had a transplant; $\mathrm{PSC}=$ primary sclerosing cholangitis.

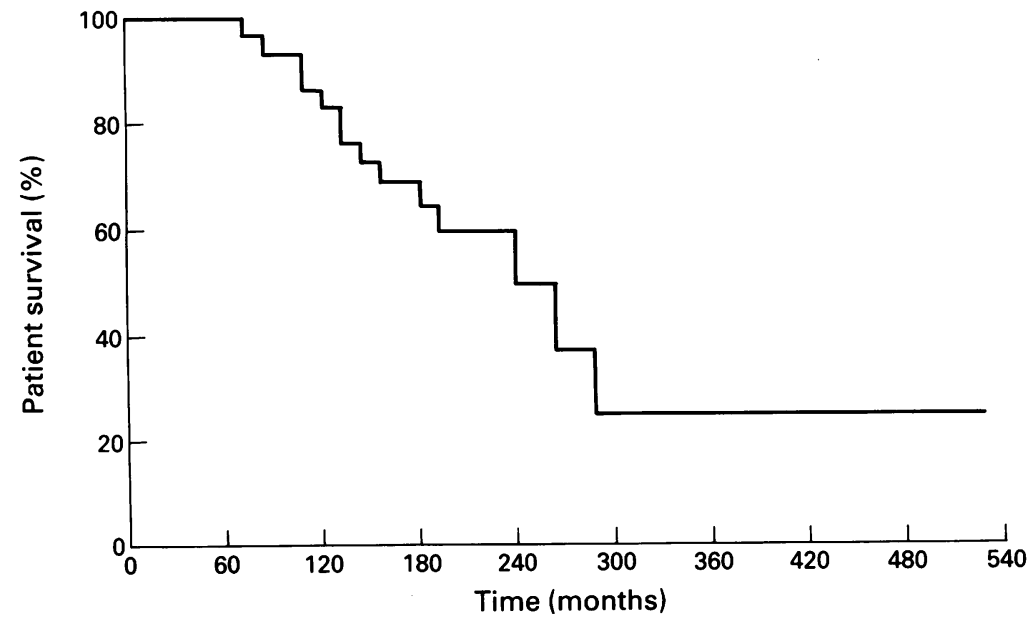

Figure 2: Survival of 29 patients with ulcerative colitis and primary sclerosing cholangitis. The estimated median time of survival is 21 years.

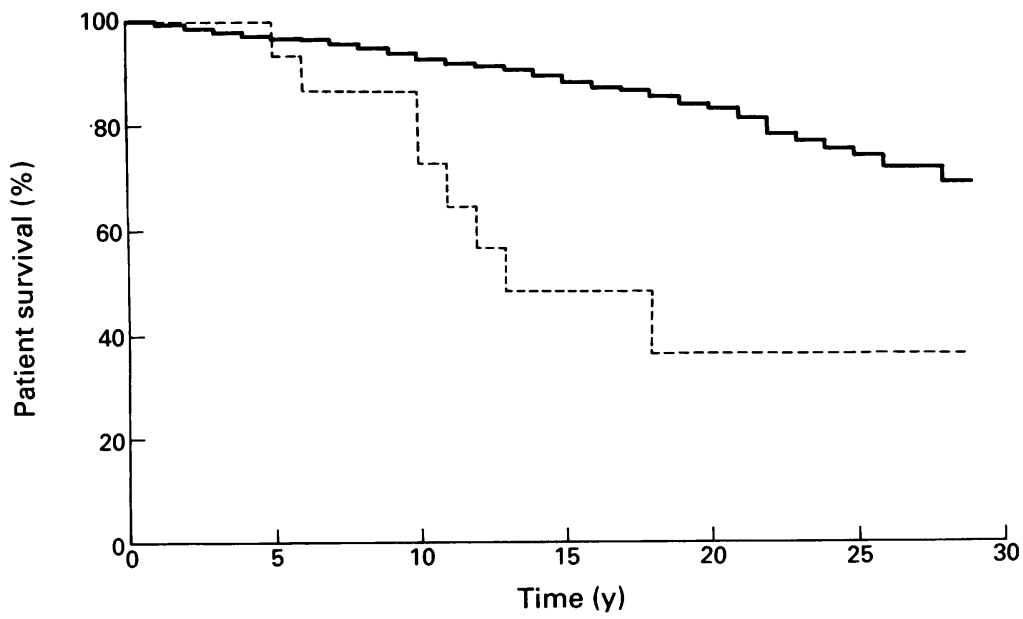

Figure 3: Actuarial survival time of 1204 patients with ulcerative colitis only (black line) compared with survival of 15 patients with primary sclerosing cholangitis and ulcerative colitis (dotted line). Survival analysis was made after a study period of 48 months. Significant differences were found between the two groups $(p<0 \cdot 0001)$.
(Table III). The male predominance was high (23/4). All but one patient had a total colitis. Six of these patients did not have a cholangiogram (five were dead at follow up) and the diagnosis was then based on clinical data including symptoms of upper right abdominal pain, pruritus, persistent cholestatic biochemical abnormalities, in combination with morphological evidence obtained from liver biopsy specimens or necropsies, or both compatible with this diagnosis. Thus, $2 \cdot 1 \%$ of all 1266 patients with ulcerative colitis also suffered from PSC. The incidence of PSC accompanied the incidence of UC, and no increase of PSC was seen during the study period (data not shown). Three of the PSC patients developed abnormal liver function tests before the onset of ulcerative colitis. In six patients, the bowel and liver disease occurred simultaneously, whereas for the other 18 PSC patients the abnormality in liver function tests began at a median time of seven years (range 2-20) after the onset of the bowel disease.

Two patients had significantly increased alkaline phosphatase activities and morphological changes in liver biopsy specimens compatible with a diagnosis of PSC. Both patients had, however, repeated normal ERCPs and were therefore believed to be suffering from sclerosing cholangitis of the small bile ducts. ${ }^{19}$ In one of these patients, histological progression of the cholangitis to bridging fibrosis and cirrhosis was noted. Taking these two patients into account $2 \cdot 3 \%$, of the UC patients had PSC.

Twelve of the PSC patients were dead at follow up, eight because of hepatic failure and four because of cholangiocarcinoma. One had a liver transplant. The median time of survival for the entire PSC group was 21 years (range 6-44) (Fig 2). Nine of the PSC patients had a colectomy. This procedure did not seem to improve the liver disease, as judged from biochemical tests.

Among the whole group of patients with UC and abnormal liver function tests, 34 died and one had a transplant during the study period (1955-91). A necropsy was carried out on all but one of the patients who died (Table IV). Among these, only three were known to have had transient abnormalities of liver function tests; the remaining 31 patients had abnormal liver function tests at death. Eighteen patients died because of liver failure or primary malignancy of the liver or bile ducts, and one patient had liver transplantation because of liver failure. Survival analysis of all UC patients with hepatobiliary dysfunction, compared with patients with UC only, did not show any significant differences (data not shown). Survival analysis of all UC patients without PSC, however, compared with patients with both UC and PSC, showed a significant reduced survival for the PSC group $(\mathrm{p}<0.0001)$ (Fig 3).

\section{Discussion}

To our knowledge, this is the first follow up study of patients with UC and concomitant abnormality in tests of liver function. All patients were originally included in an epidemiological study; selection bias can therefore be excluded. 
Transient abnormal values in the tests for liver function were found during periods of active total colitis in 40 of 142 patients. Most of these patients had total colitis, and 21 had colectomy. In some of these patients liver function abnormalities developed during the perioperative period, but did persist for at least two months. Patients with exacerbations of inflammatory bowel disease sometimes presented with raised concentrations of serum alkaline phosphatases and transaminases. ${ }^{20}$ Dew et al found that $25 \%$ of the patients operated on because of inflammatory bowel disease had transient perioperative changes in liver function. ${ }^{21}$. Half of these patients, however, suffered from postoperative wound infections or sepsis; this was not the case in our study. Transient rises in transaminases activities can also result from total parenteral nutrition. ${ }^{22}$ This was not, however, considered to be the cause in our patients. Hence, although the cause of the abnormal values in liver function tests during active colitis is not fully understood, liver function tests are indeed impaired but usually resolve spontaneously.

Fatty change of the liver is a well known abnormality in UC and also a common finding in patients having colectomy ${ }^{123}$; furthermore, this change has been suggested to be related to the severity of the colitis. ${ }^{4}$ In this study, fatty change was found in all patients with abnormal liver function tests and active colitis in which a liver biopsy specimen was obtained. Therefore, it may be suspected that the fatty change in this subgroup of UC patients is an unspecific manifestation of the accompanying malnutrition, anaemia, and treatment with corticosteroids. Eleven patients, however, had fatty change unrelated to the activity of the colitis, a finding that might be explained by overweight or overconsumption of alcohol. Fatty change is an unspecific and common cause for a rise in serum transaminase activities in asymptomatic patients and also in asymptomatic patients without UC. ${ }^{16}$

Chronic autoimmune hepatitis has been reported to be associated with ulcerative colitis. ${ }^{6}$ Because, in the quoted study, however, no clear distinction between PSC was made, some patients may well have been suffering from this disease. In our study, only three cases with autoimmune hepatitis were found. One patient was found to have primary biliary cirrhosis, previously described in association with UC in only five cases in published works. ${ }^{24} 25$

Twenty of our patients had infectious liver diseases, in particular chronic hepatitis C, most probably transmitted by blood transfusions. It may be surmised that in the group of patients with transient abnormalities in liver function tests some might be included who had received blood transfusions; acute hepatitis $\mathrm{C}$ may well have caused the rise seen in transaminase activities.

PSC was previously considered a rare disease, only five patients in our study were investigated with ERCP or percutaneous transhepatic cholangiography and diagnosed as having PSC before 1979. The number of patients with UC who developed PSC remained constant during the study period suggesting that the cause of PSC is closely linked to UC. On average, 14 years elapsed after the onset of evidence of abnormal liver function tests until the diagnosis of PSC was made. Therefore, some patients in our study who died before 1979 may well have suffered from undiagnosed PSC. The frequency of this disease in patients in this study is lower than in a recent epidemiological study of the point prevalence of PSC in patients with UC in Sweden $(2.3 v$ $3.5 \%){ }^{26}$ Patients with proctitis were not included in this study. Excluding patients with proctitis from our study increases the frequency of patients with PSC to $3 \%$. Among patients with total colitis, $6.3 \%$ were found to have PSC in this study, compared with $5 \cdot 5 \%$ in the study by Olsson et al. ${ }^{26}$ In both these studies, only patients with abnormal liver function tests were examined. As it is known that a small group of patients with PSC may have normal values in liver function tests, the true incidence of PSC may be somewhat higher than previously reported. ${ }^{27}$

Two patients (7\% of all PSC patients) were found to have small bile duct sclerosing cholangitis, an entity introduced by the Mayo group in $1985 .{ }^{19}$ In our study, these patients did not develop any large bile duct involvement although histological signs of progression were noted. This may imply that small bile duct sclerosing cholangitis is not an early stage of large bile duct sclerosing cholangitis, but rather a distinct entity representing one end of a large disease spectrum of biliary involvement in UC.

In our study four PSC patients died of cholangiocarcinoma, which is known to be associated with both UC and PSC. ${ }^{28}$ All patients with cholangiocarcinoma also had PSC; therefore it seems probable that this particular subset of patients with UC also has an increased risk of developing cholangiocarcinoma. Occurrence of cholangiocarcinoma in $14 \%(4 / 29)$ of our PSC patients is a high figure when compared with the results in other studies. ${ }^{511129}$ The explanation for the differences in the results may be that all PSC patients who died had a postmortem examination and the diagnoses could be verified whereas there are apparent problems in diagnosing cholangiocarcinoma in living patients with PSC.

Patients with PSC may have a highly variable course, many remaining well and asymptomatic during the entire study period. The estimated median time of survival for all PSC patients was 21 years (range 6-44). Recently, one study from the Mayo Clinic and one from King's College on PSC have shown an overall survival of 11.7 and 12 years, respectively. ${ }^{10}{ }^{11}$ It is important to note that in these two studies both start and endpoints of PSC were defined in different ways therefore no real comparison can be made. The English study and our study, however, both define onset of PSC as the time of the first presentation of abnormal liver function tests or symptoms consistent with the diagnosis of PSC, and endpoint as either liver related death or liver transplantation. The much higher median survival found in our study is therefore probably explained by the fact that it lacks the selection bias found in the English one.

Thus, it can be concluded that although $11 \%$ of all patients with UC presented with evidence 
of abnormal liver function tests, a return to normal occurred spontaneously in many cases. The need for blood transfusions among these patients, and the subsequent transmission of viral infections can explain the frequent finding of hepatitis among UC patients. With the increased and improved testing of blood products, infections of this kind will hopefully be something of the past in coming years. PSC is the most common chronic liver disease associated with UC. Although the median time of survival for the PSC patients in our study is much longer than described previously, patients with UC and a concurrent PSC are likely to have a significantly reduced survival time compared with patients with UC only.

This study was supported by funds from Karolinska Institute, Swedish Medical Research Council, and Ruth and Rickard Juhlin's Fund.

1 Thomas $\mathrm{CH}$. Ulceration of the colon with a much enlarged fatty liver. Trans Pathol Soc Philadelphia 1873; 4: 87-8.

2 Kimmelstein P, Large HL, Verner HD. Liver damage in ulcerative colitis. Am f Pathol 1952; 28: 259-79.

3 Kleckner MS, Stauffner MH, Bargen JA, Dockerty MB. Hepatic lesions in the living patient with chronic ulcerative colitis as demonstrated by needle biopsy. Gastroenterology 1952; 22: 13-33.

4 de Dombal FT, Goldie W, Watts JMcK, Goligher JC. Hepatic histological changes in ulcerative colitis. Scand $\mathcal{f}$ Gastroenterol 1966; 1: 220-7.

5 Akwari O, van Heerden JA, Foulk WT, Baggenstoss AH. Bile duct carcinoma associated with ulcerative colitis. Rev Surg 1976; 33: 289-93.

6 Olsson R, Hulthén L. Concurrence of ulcerative colitis and chronic active hepatitis. Clinical courses and results of colectomy. Scand F Gastroenterol 1975; 10: 331-4.

7 Schrumpf E, Elgjo K, Fausa O. Gjone E, Kolmannskog F, Ritland S. Sclerosing cholangitis in ulcerative colitis. Scand f Gastroenterol 1980; 15: 689-97.

8 Lupinetti M, Mehigan H, Cameron J. Hepatobiliary complications in ulcerative colitis. Am f Surg 1980; 139: 113-8.

9 Shepherd HA, Selby WS, Chapman RWG, Nolan D, Barbatis C, McGee JO'D et al. Ulcerative colitis and persistent liver dysfunction. $Q \mathcal{F}$ Med 1983; 52: 503-13.

10 Wiesner RH, Grambsch PM, Dickson R, Ludwig J, MacCarty $\mathrm{RL}$, Hunter EB, et al. Primary sclerosing cholangitis: natural history, prognostic factors and survival analysis. natural history, prognostic factor
Gastroenterology 1979; 4: 430-6.
11 Farrant JM, Hayllar KM, Wilkinsson ML, Karani J, Portmann BC, Westaby D, et al. Natural history and prognostic variables in primary sclerosing cholangitis. Gastroenterology 1991; 100: 1710-7.

12 Nordenvall B, Broström O, Berglund $M$, Monsén U, Nordenström J, Sörstad J, et al. Incidence of ulcerative colitis in Stockholm county 1955-1979. Scand $\mathcal{7}$ Gastroenterol 1985; 20: 311-24.

13 Evans JG, Acheson ED. An epidemiological study of ulcerative colitis and regional enteritis in the Oxford area. Gut 1965; 6: 311-24

14 Chapman RWG, Arborg BAM, Rhodes JM, Summerfield JA, Dick R, Scheuer PJ, et al. Primary sclerosing cholangitis; a review of its clinical features, cholangiography and hepatic histology. Gut 1980; 21: 870-7.

15 Sherlock S. Diseases of the liver and biliary system. 8th Ed. London: Blackwell Scientific, 1989.

16 Hultcrantz R, Glauman H, Lindberg G, Nilsson LH. Liver investigation in 149 asymptomatic patients with moderately elevated activities of serum aminotransferases. Scand $\mathcal{F}$ Gastroenterol 1986; 21: 109-13.

17 MacSween RNM, Anthony PP, Scheuer PJ. Pathology of the liver. London: Churchill Livingstone, 1989.

18 Enterline PE. Pitfalls in epidemiological research: an examination of asbestos literature. F Occup Med 1976; 18: 150-6.

19 Wee A, Ludwig J. Pericholangitis in chronic ulcerative colitis: primary sclerosing cholangitis of the small bile ducts? Ann Intern Med 1985; 102: 581-7.

20 Dordal E, Glagov S, Kirsner JB. Hepatic lesions in chronic inflammatory bowel disease. Gastroenterology 1967; 52: 23953.

21 Dew MJ, Thompson H, Allan RN. The spectrum of hepatic dysfunction in inflammatory bowel disease. $Q \mathcal{F}$ Med 1979; 148: $113-5$.

22 Bengoa JM, Hanauer SB, Sitrin MD, Baker AL, Rosenberg IH. Pattern and prognosis of liver function tests abnormalities during parenteral nutrition in inflammatory bowel disease. Hepatology 1985; 5: 79-84.

23 Eade MN. Liver disease in ulcerative colitis. Ann Intern Med $1970 ; 72: 475-87$

24 Kato $\mathrm{Y}$, Morimoto H, Unoura M, Kobayashi K, Haltori N, Nakanuma $Y$. Primary biliary cirrhosis and chronic pancreatitis in a patient with ulcerative colitis. $\mathcal{F}$ Clin Gastroenterol 1985; 7: 425-7.

25 Bush A, Mitchison H, Walt R, Baron JH, Boylston AW, Summerfield JA. Primary biliary cirrhosis and ulcerative Summerfield JA. Primary biliary cirrhosis

26 Olsson R, Danielssson A, Järneroth G, Lindström E, Lööf $L$, Rolny $\mathrm{P}$, et al. Prevalence of primary sclerosing cholangitis in patients with ulcerative colitis. Gastroenterology 1991; 100: 1319-23.

27 Balasumbramaniam K, Wiesner RH, LaRusso NF. Primary sclerosing cholangitis with normal serum alkaline phosphatase activity. Gastroenterology 1988; 95: 1395-8.

28 Rosen CB, Nagorney DM, Wiesner RH, Coffey RJ, La Russo NF. Cholangiocarcinoma complicating primary sclerosing cholangitis. Ann Surg 1991; 213: 21-5.

29 Aadland E, Schrumpf E, Fausa O, Elgjo K, Heilo A, Aakhus $\mathrm{T}$, et al. Primary sclerosing cholangitis: a long-term followup study. Scand f Gastroenterol 1987; 22: 655-64. 